\title{
Prediction of prognosis in patients with uveal melanoma using fluorescence in situ hybridisation
}

Kirtikbhai A Patel, Noel D Edmondson, Fleur Talbot, M Andrew Parsons, Ian G Rennie, Karen Sisley

\begin{abstract}
Backgroundlaims-Uveal melanoma is the commonest malignancy of the eye, with a high proportion of patients dying of metastatic disease. Tumours showing a loss of chromosome 3 and gains of chromosome 8 are associated with a worse prognosis. The efficiency of fluorescence in situ hybridisation (FISH) in determining copy numbers of these chromosomes was assessed in individual tumours and related to patient survival.

Methods-33 fresh frozen samples were analysed with centromeric probes for chromosomes 3 and 8. Patient outcomes were divided into two groups: (1) absence of genetic abnormalities (no genetic imbalance) and (2) presence of genetic abnormalities (genetic imbalance). The log rank test was used to compare survival, which was represented by KaplanMeier survival curves.

Results-Of the 33 tumours analysed, 16 showed evidence of genetic imbalances. Of these 16 tumours, 14 patients had died by the end of the study, with 10 having died of liver metastases. Of the tumours without evidence of genetic imbalances, five patients had died by the end of the study, although none had died as a result of either liver metastases or from the primary uveal melanoma. The difference in survival between the two groups was highly significant $(p<0.0001)$. reliable and efficient analysis of fresh frozen tumour specimens and is valuable in the prediction of prognosis in individuals with uveal melanomas.

(Br f Ophthalmol 2001;85:1440-1444)
\end{abstract}

Department of

Surgical and

Anaesthetic Sciences, Royal Hallamshire

Hospital, Sheffield K A Patel

Institute for Cancer Studies, University of Sheffield, Sheffield

N D Edmondson

Academic Unit of Ophthalmology and Orthoptics, Royal

Hallamshire Hospital, Sheffield

F Talbot

M A Parsons

I G Rennie

K Sisley

Correspondence to: Dr Karen Sisley, Department of Ophthalmology and Orthoptics, Royal

Hallamshire Hospital, Sheffield S10 2JF, UK

k.sisley@sheffield.ac.uk

Accepted for publication 25 June 2001

Uveal melanomas are the commonest malignancy of the eye with an annual incidence of five to seven cases per million population. ${ }^{12}$ They account for approximately $80 \%$ of all non-cutaneous melanomas, ${ }^{3}$ and are classified as either posterior, located in the choroid, or anterior, when located in the ciliary body or iris. ${ }^{4}$ Uveal melanomas invariably metastasise to the liver, with the incidence of metastases peaking usually at 2-4 years after primary enucleation. ${ }^{5}$ Thus, prognosis is generally poor, with a 5 year tumour related mortality of $16-53 \%$. $^{5}$

A number of negative prognostic indicators have been established for uveal melanomas which include a maximum tumour diameter of greater than $15 \mathrm{~mm}$; the presence of epithelioid cells; extrascleral extension; tumour location in the ciliary body; ${ }^{67}$ and the histological assessment of tumour vascular patterns. ${ }^{8}$

A number of cytogenetic studies have shown that a loss of chromosome 3 is a significant negative prognostic indicator of early relapse and poor survival. ${ }^{9-11}$ Research has also shown that a gain of chromosome 8 , principally in the form of an isochromosome $8 \mathrm{q}$, is also associated with a worse prognosis. ${ }^{10-20}$ Other research has also found that the presence of chromosome 6 abnormalities is predictive of a good prognosis even when associated with abnormalities of chromosomes 3 and $8 .^{21}$

However, cytogenetic analysis requires the short term culture of tumours followed by producing good quality metaphase spreads. This process is not only laborious but could also induce in vitro genetic changes. The possibility also exists for missing genetic changes because of the small number of cells studied. The development of fluorescence in situ hybridisation (FISH) allows the interphase cytogenetic analysis of either fresh or archival tumour tissue not only quickly, but also accurately in a large number of cells. It also allows for the examination of multiple genetic changes by the use of probes labelled with spectrally distinct fluorescent dyes. ${ }^{22}$

In this study we present the retrospective analysis of fresh frozen material from 33 patients using centromeric probes for chromosomes 3 and 8 and to correlate the analysis with patient survival.

\section{Materials and methods}

SAMPLES

Informed patient consent and ethical approval were obtained before commencing the study. A series of 33 tumour samples from 33 patients treated between 1987 and 1995 was examined. The majority of patients were treated by enucleation, with tumour material being removed immediately after the globe had been opened. Histopathological diagnosis and treatment decisions were not affected by this procedure. All tumours were categorised histopathologically according to the AFIP system of classification for uveal melanomas. ${ }^{23}$ Tumour diameter was assessed preoperatively by B scan ultrasonography (Cooper Vision) and subsequent follow up was conducted at the Department of Ophthalmology and Orthoptics, University of Sheffield. 
FLUORESCENT IN SITU HYBRIDISATION

Thirty three fresh frozen uveal melanoma tumour samples stored in optimal cutting temperature (OCT) compound were analysed using FISH. Fresh frozen samples were selected for the study, as sufficient long term follow up was available. Paraffin embedded material was also available; however, tumour samples had been fixed in glutaraldehyde and so were not suitable for FISH analysis. Each fresh frozen sample was disaggregated manually in $2-3 \mathrm{ml}$ of phosphate buffered saline (PBS) using a scalpel, with the resultant suspension being centrifuged at $1000 \mathrm{rpm}$ for 10 minutes followed by a 15 minute incubation in hypotonic solution $(0.075 \mathrm{M} \mathrm{KCl})$ at $37^{\circ} \mathrm{C}$. The sample was then centrifuged again at 1000 rpm for 10 minutes followed by fixation in 3:1 methanol:acetic acid. The fixation was repeated twice. Slides of the disaggregated tumour material were prepared a week in advance of performing the FISH.

FISH was performed as previously described. ${ }^{11}$ Briefly, slides underwent digestion in pepsin $(50 \mathrm{mg} / \mathrm{ml})$ in $0.01 \mathrm{M} \mathrm{HCl}$ at $37^{\circ} \mathrm{C}$ for 10 minutes, followed by fixation in $1 \%$ formaldehyde in PBS $+50 \mathrm{mM} \mathrm{MgCl}_{2}$. The slides were then dehydrated in an ethanol series and allowed to air dry. Denaturation was performed in $70 \%$ formamide, $2 \times \mathrm{SSC}$, and $\mathrm{pH}$ 7.0 at $70^{\circ} \mathrm{C}$ for 2 minutes. Alpha satellite centromeric probes for chromosomes 3 (D3Z1) and 8 (D8Z2) were prepared according to instructions supplied by Appligene Oncor SA and allowed to hybridise overnight at $37^{\circ} \mathrm{C}$. Post hybridisation, the slides were washed in stringency solution ( $50 \%$ formamide, $2 \times$ SSC, $\mathrm{pH} 7.0$ ) at $42^{\circ} \mathrm{C}$ for 5 minutes, which was repeated once. This was followed by two washes in $2 \times \mathrm{SSC}$ at $42^{\circ} \mathrm{C}$ for 5 minutes. Probe detection was performed using Appligene Oncor probe detection solution followed by dehydration in ethanol. The slides were subsequently counterstained with 4,6diamidino-2-phenylindole (DAPI) $(100 \mathrm{ng} / \mathrm{ml})$ in antifade. The centromeric probes for chromosomes 3 and 8 were detected using the indirect detection method with rhodamine and fluorescein isothiocyanate (FITC) respectively.

Analysis was performed using a CCD camera attached to a fluorescent microscope and controlled by a Macintosh computer, using PSI MacProbe software.

STATISTICAL ANALYSIS

For each sample, 300 cells were counted. Cells were excluded if they were clumped together or if they appeared to have been cut.

Six normal blood controls were also analysed using FISH to assess the sensitivity and specificity of the centromeric probes. Again 300 cells were counted for each sample.

Patient outcomes were divided into two groups: (1) absence of genetic abnormalities (no genetic imbalance) and (2) presence of genetic abnormalities (genetic imbalance). No genetic imbalance was defined as a cell having the normal complement of two target hybridisation signals for each chromosome (Fig 1A), and the presence of genetic imbalance was
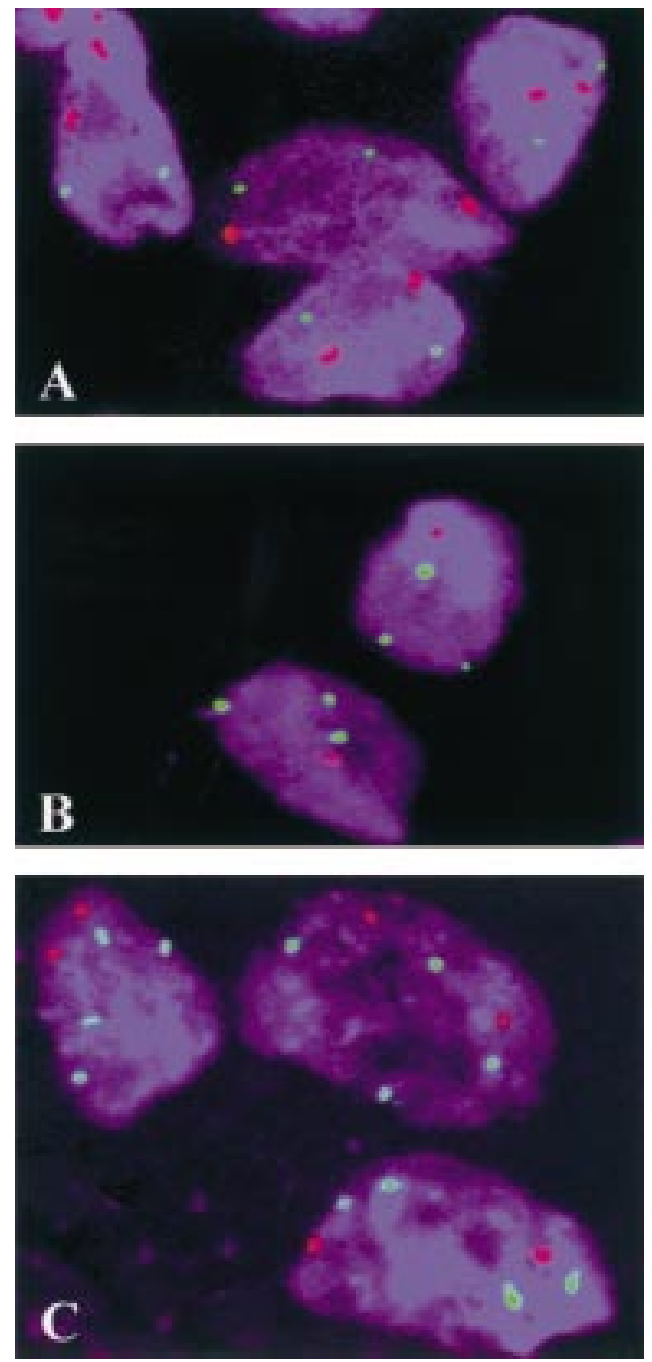

Figure 1 Three captured FISH images. (A) $A$ disaggregated uveal melanoma tissue sample with cells showing a normal complement of two target hybridisation signals for each chromosome, thus signifying no genetic imbalance. (B) An image showing cells with monosomy 3 (red target hybridisation signals, rhodamine) and trisomy 8 (green target hybridisation signals, FITC), thus signifying genetic imbalance. (C) Another image also showing genetic imbalance but with a normal complement of two hybridisation signals for chromosome 3 but with four hybridisation signals for chromosome 8.

defined as any combination of target hybridisation signals other than two for chromosome 3 and two for chromosome 8 (Fig 1B and C). Genetic imbalance was said to be present if the number of normal cells was less than $70 \%$ of the total population observed. A value of $70 \%$ was taken, as this was the sensitivity supplied in the data sheets, which was confirmed by performing FISH on the normal blood controls.

Independent samples $t$ test, $\chi^{2}$ test, or Fisher's exact test were used to assess any differences in sex, age, tumour cell types, location, and mean tumour diameter between the two groups. The log rank test was used to compare survival, which was represented by Kaplan-Meier survival curves. Statistical analysis was performed using sPss statistical software package on a PC computer. 
Table 1 Results of FISH analysis and tumour characteristics

\begin{tabular}{|c|c|c|c|c|c|c|c|c|}
\hline Patient & Sex & Age (years) & Cell type & Location & $\begin{array}{l}\text { Mean tumour } \\
\text { diameter }(\mathrm{mm})\end{array}$ & $\begin{array}{l}\text { Percentage of cells } \\
\text { with GI }\end{array}$ & Results & $\begin{array}{l}\text { Status (months } \\
\text { alive since } \\
\text { diagnosis) }\end{array}$ \\
\hline Mel 1 & $M$ & 52 & $S$ & C & 12 & 5 & No GI & A (153) \\
\hline Mel 5 & $\mathrm{~F}$ & 48 & $\mathrm{M}$ & $\mathrm{CB}$ & 4.75 & 9.33 & No GI & LFU \\
\hline Mel 7 & $M$ & 82 & $\mathrm{E}$ & $\mathrm{C}$ & 16.5 & 6 & No GI & DUR (111) \\
\hline Mel 8 & $M$ & 40 & M & $\mathrm{C}$ & 12.2 & 18.67 & No GI & A $(146)$ \\
\hline Mel 13 & $\mathrm{~F}$ & 55 & M & $\mathrm{CB} / \mathrm{C}$ & 12.7 & 8.33 & No GI & DUR (88) \\
\hline Mel 14 & $M$ & 52 & $M$ & $\mathrm{C}$ & 15.25 & 86 & GI & DLM (32) \\
\hline Mel 15 & $M$ & 56 & M & C & 11.75 & 95.3 & GI & DUK (70) \\
\hline Mel 16 & $\mathrm{~F}$ & 61 & $M$ & $\mathrm{CB} / \mathrm{C}$ & 19.75 & 81.67 & GI & DUR (14) \\
\hline Mel 21 & $M$ & 54 & $M$ & $\mathrm{CB} / \mathrm{C}$ & 16 & 3.33 & No GI & $\mathrm{A}(134)$ \\
\hline Mel 22 & $M$ & 79 & $M$ & $\mathrm{CB} / \mathrm{C}$ & 12.7 & 5.67 & No GI & DUR (44) \\
\hline Mel 24 & $\mathrm{~F}$ & 69 & $M$ & $\mathrm{C}$ & 10.05 & 9.9 & No GI & $\mathrm{A}(134)$ \\
\hline Mel 26 & M & 72 & $M$ & C & 8.5 & 33.3 & GI & DLM (55) \\
\hline Mel 28 & $\mathrm{~F}$ & 59 & $\mathrm{E}$ & $\mathrm{C}$ & 25 & 20 & No GI & DUR (128) \\
\hline Mel 31 & $\mathrm{~F}$ & 38 & Unknown & C & Unknown & 3.67 & No GI & A (204) \\
\hline Mel 36 & $M$ & 55 & $\mathrm{E}$ & Conj. & 9 & 40 & GI & DLM (40) \\
\hline Mel 37 & $\mathrm{~F}$ & 70 & $M$ & $\mathrm{CB} / \mathrm{C}$ & 15 & 43.67 & GI & DLM (8) \\
\hline Mel 40 & $\mathrm{~F}$ & 48 & M & C & 11 & 57.33 & GI & A (120) \\
\hline Mel 44 & $\mathrm{~F}$ & 76 & $M$ & $\mathrm{CB} / \mathrm{C}$ & 15.3 & 27 & No GI & A (120) \\
\hline Mel 45 & $\mathrm{~F}$ & 57 & M & C & 13.4 & 67.33 & GI & LFU \\
\hline Mel 46 & $\mathrm{~F}$ & 64 & $\mathrm{E}$ & $\mathrm{CB} / \mathrm{C}$ & 14.35 & 85 & GI & DLM (69) \\
\hline Mel 47 & $M$ & 67 & M & $\mathrm{C}$ & 13.25 & 13 & No GI & A $(118)$ \\
\hline Mel 48 & M & 35 & M & C & 15.25 & 10.33 & No GI & $\mathrm{A}(117)$ \\
\hline Mel 50 & $\mathrm{~F}$ & 48 & $M$ & $\mathrm{CB} / \mathrm{C}$ & 10.35 & 87.67 & GI & DLM (52) \\
\hline Mel 51 & $\mathrm{~F}$ & 61 & E & CB & Unknown & 95.67 & GI & DLM (26) \\
\hline Mel 52 & $\mathrm{~F}$ & 72 & M & $\mathrm{C}$ & 17 & 88.33 & GI & DUR (46) \\
\hline Mel 53 & $M$ & 46 & M & $\mathrm{CB} / \mathrm{C}$ & 15.6 & 96.33 & GI & DLM (54) \\
\hline Mel 57 & $\mathrm{~F}$ & 63 & $M$ & $\mathrm{CB} / \mathrm{C}$ & 14.75 & 94.67 & GI & DLM (38) \\
\hline Mel 68 & $M$ & 71 & $S$ & Conj & 30 & 65 & GI & DUK (19) \\
\hline Mel 69 & $\mathrm{~F}$ & 53 & M & C & 9 & 29 & No GI & $\mathrm{A}(102)$ \\
\hline Mel 71 & $M$ & 35 & $\mathrm{~S}$ & $\mathrm{C}$ & 13.45 & 1.33 & No GI & $\mathrm{A}(100)$ \\
\hline Mel 73 & $M$ & 64 & M & $\mathrm{CB} / \mathrm{C}$ & 20.6 & 7.33 & No GI & DUK (63) \\
\hline Mel 75 & $\mathrm{~F}$ & 70 & $\mathrm{~S}$ & $\mathrm{C}$ & 12.3 & 6.33 & No GI & $\mathrm{A}(98)$ \\
\hline Mel 94 & M & 33 & M & $\mathrm{C}$ & 16.6 & 100 & GI & DLM (17) \\
\hline
\end{tabular}

$\mathrm{M}=$ male; $\mathrm{F}=$ female; $\mathrm{E}=$ epithelioid $\mathrm{M}=$ mixed; $\mathrm{S}=$ spindle $\mathrm{C}=$ choroid $\mathrm{CB}=$ ciliary body; Conj = conjunctiva; $\mathrm{A}=$ alive; $\mathrm{DLM}=$ died with liver metastases; DUR $=$ died of unrelated causes; DUK $=$ died of unknown causes; LFU = lost to follow up. GI = genetic imbalance present; No GI $=$ no genetic imbalance present.

\section{Results}

All the normal blood samples showed normal constitutional hybridisation signals for chromosomes 3 and 8 (that is, two hybridisation signals each for both chromosomes) in between $80 \%$ and $90 \%$ of cases. This was in keeping with data specifications supplied by Appligene Oncor, which stated that a normal sample of cells would show two hybridisation signals for each chromosome in $70 \%$ of cells analysed.

Of the 33 tumours analysed, 16 showed evidence of genetic imbalances. Of these 16 tumours, 14 patients had died by the end of the study, with 10 having died of liver metastases. The cause of death was unknown in two patients, with the rest having died of unrelated causes. The median duration of survival for these patients was 37 months (14-52 months). Of the tumours without evidence of genetic imbalances, five patients had died by the end of the study, although none had died as a result of either liver metastases or from the primary uveal melanoma. The median duration of survival for these patients was 114 months (44-204 months) (Table 1). Two patients were lost to follow up, one from each group and were thus excluded from the survival analyses.

Of the 16 tumours that showed genetic imbalance, imbalance was due to a loss of chromosome 3 in 15 of these cases, with associated gains of chromosome 8 in three tumours only. Only one tumour had a gain of chromosome 8 not associated with a loss of chromosome 3 (Mel 50) where the patient died due to liver metastases and survived only 52 months (Table 1). The results obtained using FISH were in accord with previous cytogenetic analyses in several tumours (Mel 22, 36, 37, $40,52,53$, and 57) and discordant in two tumours (Mel 14 and 44), where cytogenetic analysis was incomplete, as a result of insufficient material. ${ }^{11}$

If only those deaths due to liver metastases are considered, the difference between the two groups is statistically significant $(p<0.0001)$. However, even if it is assumed that all patients who died may have had occult metastases, the difference between the two groups is still statistically significant $(p<0.0001)$. Both scenarios are represented by the Kaplan-Meier survival curves (Figs 2 and 3 ).

No significant differences were observed in sex $(p=0.732)$, age $(p=0.889)$, tumour cell type $(p=0.73)$, location $(p=0.498)$, or mean tumour

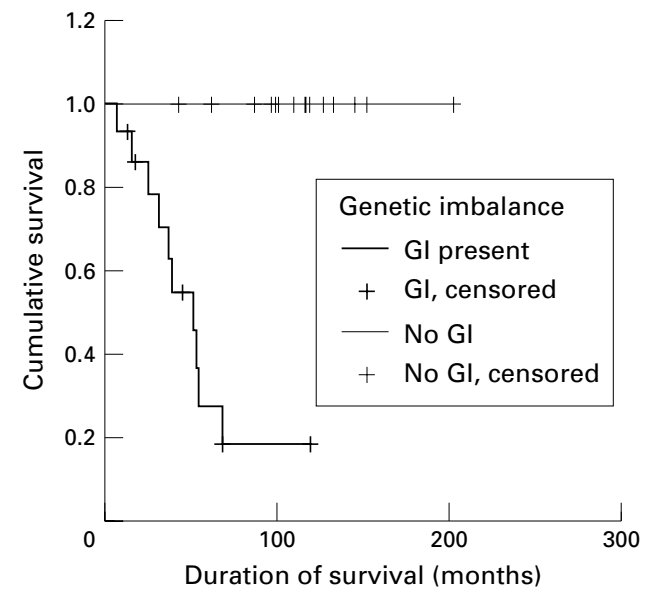

Figure 2 Kaplan-Meier survival curve for deaths due to liver metastases. 


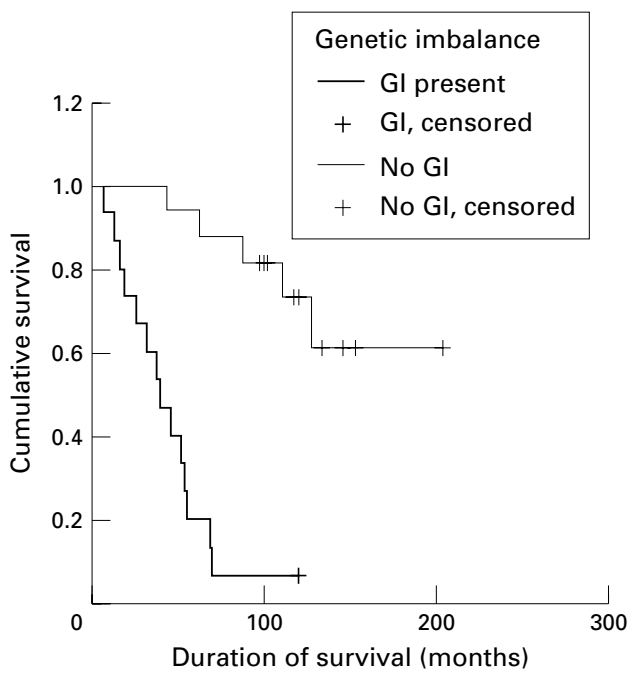

Figure 3 Kaplan-Meier survival curve for all deaths.

diameter $(p=0.574)$ between the two groups (Table 2).

\section{Discussion}

Genetic imbalance of chromosome 3 and 8 represents a significant risk factor for metastatic disease and reduced survival in patients with uveal melanoma. Clinically significant genetic imbalances can occur as a result of a single loss of chromosome 3 ; a loss of chromosome 3 associated with gains of chromosome 8; or rarely from a single or multiple gains of chromosome 8. Conversely, the absence of any genetic imbalance, with diploid tumour cells, appears to predict for a better prognosis.

A level of $70 \%$ was used as a cut-off point for the assessment of imbalance, since two probes were being used synchronously and the manufacturer's sensitivity for each probe was stated as $70 \%$. Although the normal blood samples exhibited a normal constitutional ratio in $80-90 \%$ of cells, declaring genetic imbalance in tumours where the number of normal cells was less than $80 \%$-in other words the number of cells exhibiting genetic imbalance exceeded $20 \%$ rather than 30\%-two additional tumours (Mel 44 and 69) would have been declared as showing genetic imbalance; in both cases the patients are still alive having survived for over 100 months. However, the differences in survival between the two groups would still be significant $(p<0.0005)$. It is important to consider at what level of genetic imbalance is important in determining prognosis-for instance, in the case of Mel 26, just over $30 \%$ of cells analysed showed genetic imbalance where the patient died of liver metastases. It is possible that in the long term even patients with minimal genetic imbalance, in the region of $5-10 \%$, will ultimately proceed to develop metastatic disease, but at this level any inaccuracies of technique could lead to an increase in the number false positives.

A previous study by McNamara et al, who performed FISH analyses on 17 choroidal and five conjunctival melanoma specimens using chromosome 3 centromeric probes, found monosomy 3 in two choroidal tumours (12\%), whereas in this study 13 of 30 patients with choroidal tumours (43\%) exhibited monosomy 3 of which eight had died of confirmed liver metastases. Although, overall, the incidence of monosomy 3 was higher in our study, this may reflect a higher proportion of tumours with ciliary body involvement, which are more likely to be associated with monosomy $3 .^{11}{ }^{21}$ The long term clinical relevance in the study by McNamara et al was not established. ${ }^{24}$ The use of centromeric probes in this study only allows for the analysis of copy numbers of either chromosome. Therefore, subtle sequence changes such as base substitutions, deletions, or insertions will be missed, as will chromosome translocations. ${ }^{22}$ Several tumour suppressor genes may reside on chromosome 3, the loss of which may result in tumour progression, metastatic disease, and reduced survival. ${ }^{25}$ The gain of chromosome 8 , especially $8 \mathrm{q}$, has also been seen in a number of other tumours, suggesting the presence of either a single or multiple potential oncogenes. ${ }^{26}{ }^{27} \mathrm{With}$ further developments in the mapping and sequencing of tumour suppressor genes and oncogenes involved in uveal melanoma metastasis, the sensitivity and specificity of this technique could be improved further.

Interestingly, no significant difference was observed in tumour cell type, tumour location, or mean tumour diameter, which was found in other studies..$^{2-6} 7$ This may have been as a result of the small numbers of tumours present in each group.

Table 2 Results of statistical analysis

\begin{tabular}{|c|c|c|c|}
\hline & Genetic imbalance absent (No GI) & Genetic imbalance present (GI) & $\begin{array}{l}p \text { Value for } \\
\text { difference }\end{array}$ \\
\hline Number of patients & 17 & 16 & \\
\hline $\operatorname{Sex} M / F$ & $9 / 8$ & $7 / 9$ & 0.732 \\
\hline \multicolumn{4}{|l|}{ Age (years) } \\
\hline Mean (SD) & $57.41(15.18)$ & $58.06(10.96)$ & \multirow[t]{2}{*}{0.889} \\
\hline Median & 55 & 59 & \\
\hline Tumour diameter (mm) & Incomplete data for 1 tumour & Incomplete data for 1 tumour & \multirow{3}{*}{0.574} \\
\hline Mean (SD) & $13.82(4.60)$ & $14.82(5.23)$ & \\
\hline Median & 12.975 & 14.75 & \\
\hline Cell type & Incomplete data for 1 tumour & & \multirow{4}{*}{0.730} \\
\hline Spindle & 3 & 1 & \\
\hline Mixed & 11 & 12 & \\
\hline Epithelioid & 2 & 3 & \\
\hline \multicolumn{4}{|l|}{ Location } \\
\hline Choroid & 7 & 11 & \multirow{4}{*}{0.498} \\
\hline Ciliary body & 1 & 1 & \\
\hline Ciliary body/choroid & 6 & 5 & \\
\hline Conjunctiva & 2 & 0 & \\
\hline
\end{tabular}


Liver resection surgery for liver metastases from colorectal cancers has been effective in improving survival and quality of life. ${ }^{28}{ }^{29} \mathrm{How}-$ ever, there have been few reported studies on the effectiveness of resection of liver metastases from uveal melanomas, as metastases tend to present late and at multiple sites within the liver. ${ }^{30}$ Similarly, chemotherapy has also failed to show significant benefit in patients with extensive disease. ${ }^{31}$ However, combination therapy with surgery and local chemotherapy may provide benefit in selected patients. ${ }^{30} 3233$ The potential to identify high risk patients could allow these patients to be monitored more closely for the presence of liver metastases or be offered adjuvant chemotherapy at an earlier stage.

We have shown that FISH analysis for chromosome 3 and 8 is a reliable and efficient technique in the analysis of fresh frozen tumour specimens and is valuable in the prediction of prognosis in individuals with uveal melanomas. Further large scale prospective studies will be required to define the sensitivity and specificity of this technique in clinical practice.

We gratefully acknowledge funding from Yorkshire Cancer Research and the help of Mrs Rhona Jacques with the collection of the clinical data and Miss Rosie Taylor with the statistica analysis.

1 Egan KM, Seddon JM, Glynn RJ, et al. Epidemiologic spects of uveal melanoma. Surv Ophthalmol 1988;32:239 51.

2 Jensen OA. Malignant melanomas of the human uvea 25-year follow-up of cases in Denmark, 1943-1952. Acto Ophthalmol (Copenh) 1982;60:161-82.

3 Scotto J, Fraumeni JF Jr, Lee JA. Melanomas of the eye and other noncutaneous sites: epidemiologic aspects. I Nat Cancer Inst 1976;56:489-91.

4 Char DH. Clinical ocular oncology. 2nd ed. Philadelphia: Lippincott-Raven Publishers, 1997.

5 Diener-West M, Hawkins BS, Markowitz JA, et al. A review of mortality from choroidal melanoma. II. A meta-analysis of 5-year mortality rates following enucleation, 1966 through 1988. Arch Ophthalmol 1992;110:245-50.

6 Coleman K, Baak JP, Van Diest P, et al. Prognostic factors following enucleation of 111 uveal melanomas. $\mathrm{Br} \mathcal{F}$ Ophthalmol 1993; 77:688-92.

7 McLean IW, Foster WD, Zimmerman LE. Uveal melanoma: location, size, cell type, and enucleation as risk factors in metastasis. Hum Pathol 1982;13:123-32.

8 Folberg R, Rummelt V, Parys-Van Ginderdeuren R, et al. The prognostic value of tumor blood vessel morphology in primary uveal melanoma. Ophthalmology 1993;100:138998.

9 Prescher G, Bornfeld N, Becher R. Nonrandom chromosomal abnormalities in primary uveal melanoma. $\mathcal{F}$ Nat Cancer Inst 1990;82:1765-9.

10 Prescher G, Bornfeld N, Hirche H, et al. Prognostic implications of monosomy 3 in uveal melanoma. Lancet 1996;347:1222-5.
11 Sisley K, Rennie IG, Parsons MA, et al. Abnormalities of chromosomes 3 and 8 in posterior uveal melanoma correate with prognosis. Genes Chromosomes Cancer 1997;19:22-

12 Dahlenfors R, Tornqvist G, Wettrell K, et al. Cytogenetical observations in nine ocular malignant melanomas. Anticancer Res 1993;13:1415-20.

13 Horsman DE, Sroka H, Rootman J, et al. Monosomy 3 and isochromosome $8 \mathrm{q}$ in a uveal melanoma. Cancer Genet Cytogenet 1990;45:249-53.

14 Horsman DE, White VA. Cytogenetic analysis of uveal melanoma. Consistent occurrence of monosomy 3 and trisomy 8q. Cancer 1993;71:811-9.

15 Horsthemke B, Prescher G, Bornfeld N, et al. Loss of chromosome 3 alleles and multiplication of chromosome 8 alleles in uveal melanoma. Genes Chromosomes Cancer 1992;4: 217-21.

16 Prescher G, Bornfeld N, Horsthemke B, et al. Chromosomal aberrations defining uveal melanoma of poor prognosis. Lancet 1992;339:691-2.

17 Singh AD, Boghosian-Sell L, Wary KK, et al. Cytogenetic findings in primary uveal melanoma. Cancer Genet Cytogenet 1994;72:109-15.

18 Sisley K, Rennie IG, Cottam DW, et al. Cytogenetic findings in six posterior uveal melanomas: involvement of chromosomes 3, 6, and 8. Genes Chromosomes Cancer 1990;2:2059.

19 Sisley K, Cottam DW, Rennie IG, et al. Non-random abnormalities of chromosomes 3,6 , and 8 associated with posterior uveal melanoma. Genes Chromosomes Cancer 1992;5: 197-200.

20 Wiltshire RN, Elner VM, Dennis T, et al. Cytogenetic analysis of posterior uveal melanoma. Cancer Genet Cytogenet 1993;66:47-53.

21 White VA, Chambers JD, Courtright PD, et al. Correlation of cytogenetic abnormalities with the outcome of patients with uveal melanoma. Cancer 1998;83:354-9.

22 Kallioniemi A, Visakorpi T, Karhu R, et al. Gene copy number analysis by fluorescence in situ hybridization and comparative genomic hybridization. Methods 1996;9:113-

23 Spencer. Ophthalmic pathology. An atlas and textbook. Vol 3. Philadelphia: WB Saunders, 1986.

24 McNamara M, Felix C, Davison EV, et al. Assessment of chromosome 3 copy number in ocular melanoma using fluorescence in situ hybridization. Cancer Genet Cytogenet 1997;98:4-8.

25 Kok K, Naylor SL, Buys CH. Deletions of the short arm of chromosome 3 in solid tumors and the search for suppressor genes. Adv Cancer Res 1997;71:27-92.

26 Singh AD, Wang MX, Donoso LA, et al. Genetic aspects of melanoma: a brief review. Semin Oncol 1996;23:76872.

27 Cree IA. Cell cycle and melanoma-two different tumours from the same cell type. $\mathcal{F}$ Pathol 2000;191:112-4.

28 Ambiru S, Miyazaki M, Isono T, et al. Hepatic resection for colorectal metastases: analysis of prognostic factors. Dis Colon Rectum 1999;42:632-9.

29 Harmon KE, Ryan JA Jr, Biehl TR, et al. Benefits and safety of hepatic resection for colorectal metastases. Am f Surg 1999;177:402-4

30 Salmon RJ, Levy C, Plancher C, et al. Treatment of liver metastases from uveal melanoma by combined surgerychemotherapy. Eur f Surg Oncol 1998;24:127-30. 31 Kath R, Hayungs J, Bornfeld N, et al. Prognosis and
treatment of disseminated uveal melanoma. Cancer 1993; 72:2219-23.

32 Pyrhonen S. The treatment of metastatic uveal melanoma. Eur f Cancer 1998;34(Suppl 3):S27-30.

33 Woll E, Bedikian A, Legha SS. Uveal melanoma: natural history and treatment options for metastatic disease. Melanoma Res 1999;9:575-81. 